\title{
Pearls \& Oy-sters: Rheumatoid meningitis occurring during treatment with etanercept
}

Nicoleta Gherghel, MD,* Adina Stan, MD, PhD,* and Horatiu Stan, MD, PhD

Correspondence

Dr. Gherghel

nicoleta_gherghel1940@

yahoo.com

\section{Pearls}

- Rheumatoid meningitis is a rare condition that can manifest as cognitive impairment, focal neurologic signs, cranial nerve dysfunction, seizures, and headache.

- Suspicious neuroimaging findings include fluid-attenuated inversion recovery (FLAIR) hyperintensities along the meninges and subarachnoid space as well as enhancement of meninges on gadolinium-enhanced T1-weighted images.

- Meningeal biopsy reveals infiltration of mononuclear cells, vasculitis, and rheumatoid nodules.

- Treatment includes corticosteroids alone or in combination with azathioprine, cyclophosphamide, methotrexate, or rituximab.

\section{Oy-sters}

- Rheumatoid meningitis can occur despite longstanding treatment with anti-tumor necrosis factor -(TNF) $-\alpha$ agents.

- Differential diagnosis includes infectious meningitis, vasculitis, neurosarcoidosis, neurosyphilis, leptomeningeal carcinomatosis, and drug-induced meningitis.

- Nonspecific lumbar puncture findings and asymmetric involvement on MRI should not lead one away from the diagnosis, since these are common findings in rheumatoid meningitis.

\section{Case description}

A 77-year-old woman with a long-standing history of rheumatoid arthritis (RA) being treated with etanercept and leflunomide for 9 years presented with multiple episodes of speaking difficulty and paresthesia in her left limbs. These episodes started 1 month prior to admission. Initially, symptoms occurred once or twice a week, then gradually increased in frequency to become daily. Each episode lasted approximately 10-20 minutes.

On admission, the patient was noted to have temporal disorientation, intermittent dysarthria, and left hemiparesis predominantly affecting the leg (with a Medical Research Council score of $4 / 5$ in the lower limb and 4+/5 in the upper limb). RA symptoms were well-controlled with treatment. The patient reported no articular pain or signs of active inflammation.

Brain MRI revealed abnormalities over the right hemisphere. FLAIR images showed effacement of sulci and hyperintense signal along the leptomeninges and subarachnoid space. Diffusion-weighted imaging showed diffuse areas of diffusion restriction along the right subarachnoid space but no signs of acute ischemic stroke. Postcontrast T1-weighted images showed enhancement of leptomeninges and pachymeninges (figure, A and B). Carotid ultrasound and transcranial color Doppler results were normal. Based on these findings, the differential diagnosis included infectious meningitis, vasculitis, meningeal metastases, neurosarcoidosis, neurosyphilis, and rheumatoid meningitis (RM).

\footnotetext{
*These authors contributed equally to this work.
}

From the Neurology Clinic (N.G.), Emergency County Hospital; and Neurosciences Department (A.S.) and Neurosurgery Department (H.S.), University of Medicine and Pharmacy "Iuliu Haţieganu," Cluj-Napoca, Romania.

Go to Neurology.org/N for full disclosures. Funding information and disclosures deemed relevant by the authors, if any, are provided at the end of the article. 


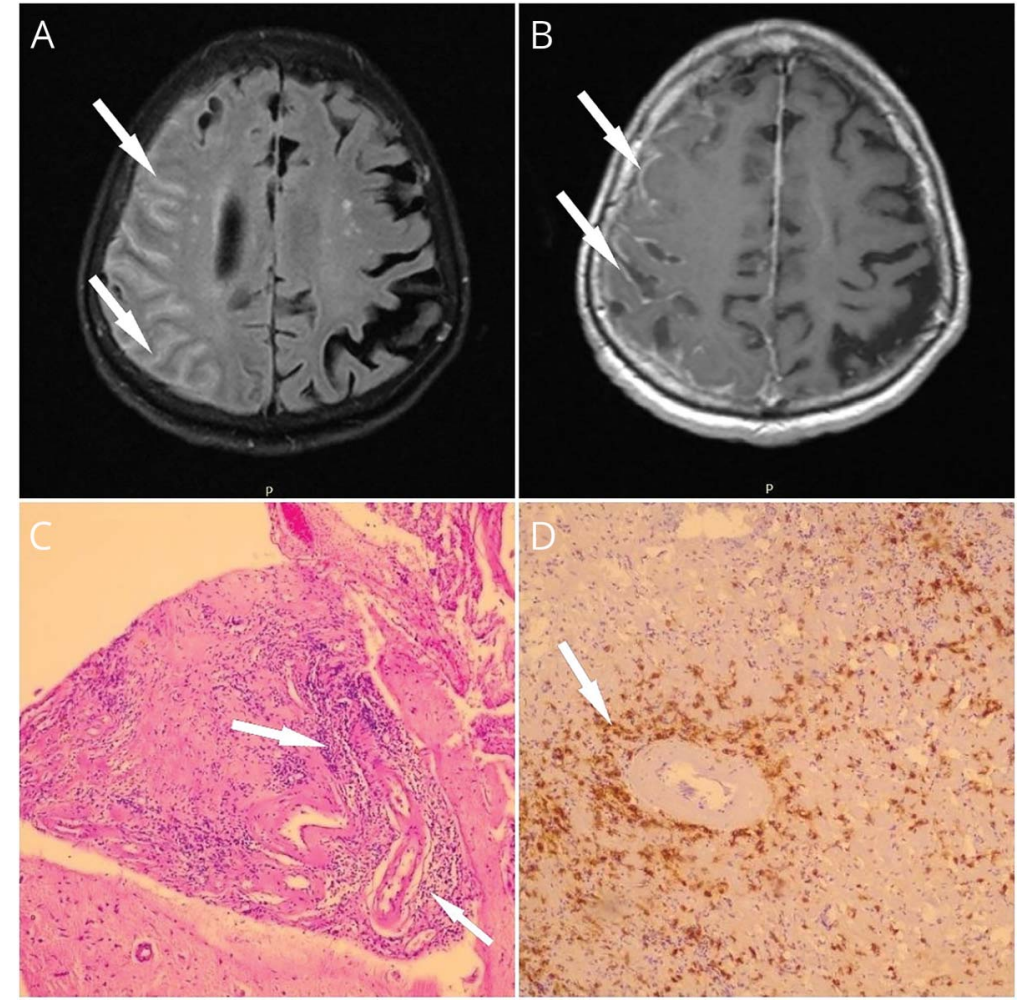

(A)Axial fluid-attenuated inversion recovery image shows effacement of sulci and high signal intensities along the leptomeninges and subarachnoid space of the right hemisphere. (B) Axial contrast-enhanced T1-weighted image shows leptomeningeal enhancement over the right hemisphere. (C) Perivascular inflammatory infiltrate on hematoxylin \& eosin stain $(\times 10)$. (D) CD68 immunostain reveals CD68+ perivascular histiocytes $(\times 10)$.
Serum antibody profile was performed, showing elevated levels of rheumatoid factor $(86 \mathrm{IU} / \mathrm{mL}$, normal values $[\mathrm{nv}]<14$ $\mathrm{IU} / \mathrm{mL})$, anticitrullinated protein antibodies $(119 \mathrm{U} / \mathrm{mL}, \mathrm{nv}<$ $5 \mathrm{IU} / \mathrm{mL})$, and antinuclear antibodies (1/160, nv negative). Serum angiotensin-converting enzyme, peripheral blood smear, syphilis, and HIV serology were normal. Pulmonary $\mathrm{X}$-rays showed right upper lobe round opacities previously diagnosed as rheumatoid nodules. The EEG showed a posterior dominant, symmetric, reactive, low-amplitude, and poorly organized alpha rhythm. There were no epileptiform discharges, and the typical clinical episode was not captured. MiniMental State Examination showed a mild cognitive deficit (20/ 30 points) with memory and executive function impairments.

CSF analysis revealed a slightly elevated protein level (49 mg/ $\mathrm{dL}, \mathrm{nv} 15-45 \mathrm{mg} / \mathrm{dL}$ ) and white blood cell count (5 cells/ $\mathrm{mm}^{3}$, with predominance of lymphocytes, $\mathrm{nv}<3$ cells $/ \mathrm{mm}^{3}$ ). Mycobacterium tuberculosis PCR test, bacterial and fungal cultures, cytology for malignant cells, and venereal disease research laboratory test were negative.

A meningeal biopsy was performed, revealing vasculitis with leptomeningeal perivascular inflammatory infiltrate (consisting mainly of plasmacytes and CD68+ histiocytes) and large areas of perivascular necrosis. Rheumatoid nodules were not reported and the adjacent brain parenchyma was not affected (figure, C and D). No infection or malignancy was noted after cultures and immunostaining.
The findings were consistent with RM. Etanercept and leflunomide were discontinued and high-dose corticosteroid therapy was initiated with IV methylprednisolone $1,000 \mathrm{mg} /$ d for 3 consecutive days. Afterwards, the patient received methylprednisolone $32 \mathrm{mg}$ oral per day with gradual tapering over a period of 2 months together with azathioprine $50 \mathrm{mg}$ oral per day. This treatment led to the improvement of dysarthria, paresthesia, and temporal disorientation. Brain MRI performed 1 month after presentation showed near-complete resolution of the right hemispheric abnormalities.

At 3-month follow-up, there was no longer any temporal disorientation or paresthesias. The patient reported only occasional dysarthria, but persistent articular pain and stiffness. At the time, the treatment included $50 \mathrm{mg}$ azathioprine twice a day. Consequently, the patient was referred to a rheumatologist for rituximab initiation.

\section{Discussion}

RA targets mainly joints but can also have neurologic manifestations. Commonly, neurologic symptoms arise from osseous compression, leading to peripheral neuropathy or compressive myelopathy. Entities involving the CNS, such as progressive multifocal leukoencephalopathy (PML) and RM, are rarely described. ${ }^{1} \mathrm{RM}$ is usually the result of the underlying disease, as opposed to PML, which is thought to 
result from the immunosuppressive therapy. A recent review reports only 48 biopsy-confirmed RM cases. ${ }^{2}$

RM primarily manifests with focal neurologic signs and cranial nerve dysfunction, together with cognitive impairment, seizures, and headache. ${ }^{2}$ Ischemic-like events are rarely reported, with only 2 previous case reports describing TIA-like ${ }^{3}$ and stroke-like ${ }^{4}$ episodes.

Asymmetric meningeal involvement is a common finding in $\mathrm{RM}$; a recent review reported unilateral lesions on MRI in $62 \%$ of the cases. ${ }^{5}$ Even though brain MRI and CSF analysis are helpful to support the diagnosis, confirmation relies on meningeal histopathologic examination, which can reveal mononuclear cells infiltrate, vasculitis, or rheumatoid nodules. Despite a lack of clear guidelines for the treatment of RM, corticosteroids alone or combined with azathioprine, cyclophosphamide, methotrexate, or rituximab have been recommended. ${ }^{2}$

This case is peculiar given that RM in this patient began during biological therapy. To our knowledge, RM arising after long-standing etanercept treatment has not been described previously. Only 2 prior RM cases have been reported after etanercept treatment initiation, both diagnosed after a few months of treatment. ${ }^{6,7}$ Another case report described RM arising shortly after adalimumab introduction. ${ }^{8}$

The mechanisms that allow such inflammation to develop during treatment with etanercept remain unclear. Although not necessary for diagnosis, meningeal rheumatoid nodules are sometimes found in patients with RM. It is known that the development of rheumatoid nodules requires the presence of histiocytes, lymphocytes, plasma cells, and giant cells. Unlike other anti-TNF- $\alpha$ agents, etanercept is not able to entirely prevent accumulation of these cells in some tissues other than synovium. Possible mechanisms include selective permission of cell trafficking in certain tissues, failure to inhibit apoptosis of component cells, or failure to inhibit interferon- $\gamma$, which is known to promote granulomatosis. ${ }^{9}$ This could explain why etanercept is not entirely able to prevent rheumatoid nodule formation or to hinder the progression of meningeal inflammation in RM.

Furthermore, one of the main findings in RM is leptomeningeal vasculitis. Anti-TNF- $\alpha$ agents are known to be associated with leukocytoclastic vasculitis, through accumulation of TNF- $\alpha$ /anti-TNF- $\alpha$ immune complexes in the wall of small vessels or antibody-mediated immune disturbances caused by overactivation of the type 2 T-helper immune response. ${ }^{10}$ These mechanisms could account for the leptomeningeal vasculitis seen in patients with RM on treatment with anti-TNF- $\alpha$ agents such as etanercept.

This case illustrates RM presenting with transient neurologic symptoms and arising despite long-standing etanercept treatment. The symptoms are likely due to inflammatory cortical lesions. RM is a rare manifestation of RA. The underlying pathophysiology remains unclear and requires further studies.

\section{Author contributions}

Nicoleta Gherghel: design and conceptualization of the study, analysis and interpretation of the data, drafting and revising the manuscript. Adina Stan: design and conceptualization of the study, analysis and interpretation of the data, drafting and revising the manuscript. Horatiu Stan: major role in the acquisition of data, revising the manuscript.

\section{Acknowledgment}

The authors thank Denis Pavăl, MD (Södra Älvsborg Hospital, Sweden), for support and comments on this work.

\section{Study funding}

No targeted funding reported.

\section{Disclosure}

The authors report no disclosures relevant to the manuscript. Go to Neurology.org/ $\mathrm{N}$ for full disclosures.

\section{References}

1. Sofat N, Malik O, Higgens CS. Neurological involvement in patients with rheumatic disease. QJM 2006;99:69-79.

2. Magaki S, Chang E, Hammond RR, et al. Two cases of rheumatoid meningitis. Neuropathology 2016;36:93-102.

3. Seago S, Stroberg E, Metting A. Rheumatoid meningitis associated with infliximab. Proc Baylor Univ Med Center 2016;29:204-206.

4. Bourgeois P, Rivest J, Bocti C. Rheumatoid meningitis presenting with stroke-like episodes. Neurology 2014;82:1564-1565.

5. Choi SJ, Ho Park Y, Kim JA, Han JH, Choe G, Kim S. Pearls \& Oy-sters: asymmetric meningeal involvement is a common feature of rheumatoid meningitis. Neurology 2017;88:e108-e110.

6. Booker MJ, Flint J, Saravana S. Aseptic meningitis in a patient taking etanercept for rheumatoid arthritis. Cases J 2008;1:364

7. Tsuzaki K, Nakamura T, Okumura H, Tachibana N, Hamano T. Rheumatoid meningitis occurring during etanercept treatment. Case Rep Neurol Med 2017;2017: 7638539.

8. Huys AC, Guerne PA, Horvath J. Rheumatoid meningitis occurring during adalimumab and methotrexate treatment. Joint Bone Spine 2012;79:90-92.

9. Furst DE, Wallis R, Broder M, Beenhouwer DO. Tumor necrosis factor antagonists: different kinetics and/or mechanisms of action may explain differences in the risk for developing granulomatous infection. Semin Arthritis Rheum 2006;36:159-167.

10. Guillevin L, Mouthon L. Tumor necrosis factor- $\alpha$ blockade and the risk of vasculitis. J Rheumatol 2004;31:1885-1887. 


\section{Neurology}

Pearls \& Oy-sters: Rheumatoid meningitis occurring during treatment with etanercept Nicoleta Gherghel, Adina Stan and Horatiu Stan

Neurology 2018;91;806-808

DOI 10.1212/WNL.0000000000006397

This information is current as of October 22, 2018

\section{Updated Information \&} Services

\section{References}

Subspecialty Collections

\section{Permissions \& Licensing}

\section{Reprints}

including high resolution figures, can be found at: http://n.neurology.org/content/91/17/806.full

This article cites 10 articles, 3 of which you can access for free at: http://n.neurology.org/content/91/17/806.full\#ref-list-1

This article, along with others on similar topics, appears in the following collection(s):

All Clinical Neurology

http://n.neurology.org/cgi/collection/all_clinical_neurology

Autoimmune diseases

http://n.neurology.org/cgi/collection/autoimmune_diseases

Meningitis

http://n.neurology.org/cgi/collection/meningitis

MRI

http://n.neurology.org/cgi/collection/mri

Vasculitis

http://n.neurology.org/cgi/collection/vasculitis

Information about reproducing this article in parts (figures,tables) or in its entirety can be found online at:

http://www.neurology.org/about/about_the_journal\#permissions

Information about ordering reprints can be found online:

http://n.neurology.org/subscribers/advertise

Neurology ${ }^{\circledR}$ is the official journal of the American Academy of Neurology. Published continuously since 1951, it is now a weekly with 48 issues per year. Copyright @ 2018 American Academy of Neurology. All rights reserved. Print ISSN: 0028-3878. Online ISSN: 1526-632X.

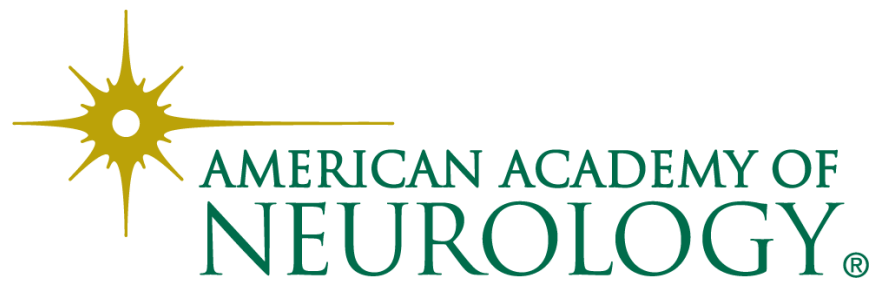

